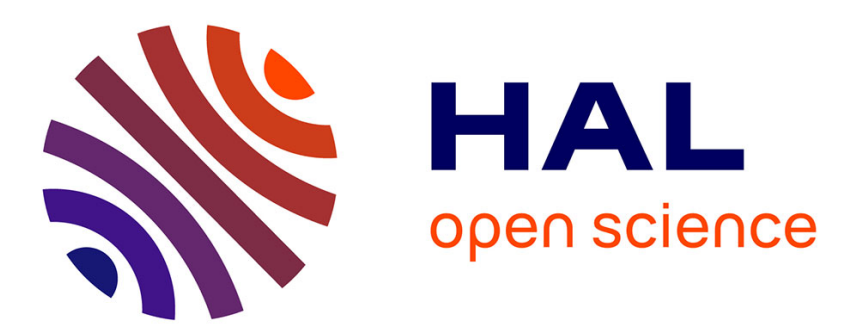

\title{
Probabilistic modeling framework for multisource sound mapping
}

Pierre Aumond, Léo Jacquesson, Arnaud Can

\section{To cite this version:}

Pierre Aumond, Léo Jacquesson, Arnaud Can. Probabilistic modeling framework for multisource sound mapping. Applied Acoustics, 2018, 139, pp.34 - 43. 10.1016/j.apacoust.2018.04.017 . hal01808868

\section{HAL Id: hal-01808868 \\ https://hal.science/hal-01808868}

Submitted on 6 Jun 2018

HAL is a multi-disciplinary open access archive for the deposit and dissemination of scientific research documents, whether they are published or not. The documents may come from teaching and research institutions in France or abroad, or from public or private research centers.
L'archive ouverte pluridisciplinaire HAL, est destinée au dépôt et à la diffusion de documents scientifiques de niveau recherche, publiés ou non, émanant des établissements d'enseignement et de recherche français ou étrangers, des laboratoires publics ou privés. 


\title{
1 Probabilistic modeling framework for multisource sound mapping
}

Pierre Aumond $^{\mathrm{a}}$, Léo Jacquesson ${ }^{\mathrm{a}}$, Arnaud Can ${ }^{\mathrm{a}}$

${ }^{a}$ IFSTTAR, CEREMA, UMRAE, F-44344 Bouguenais, France

\begin{abstract}
The process of modeling noise maps is now well defined: long-term aggregated indicators are calculated based on a collection or estimation of road, air and rail traffic variables. This framework however disregards the sound levels variations, and hence prevents the production of statistical or emergence indicators, and does not allow for the study of competition between typical urban sound sources that can improve the characterization of urban sound environments. A modeling framework in four steps is proposed to answer these issues: (i) a spatial distribution of the potential sound source of interest, (ii) the calculation of a sound propagation matrix, (iii) the stochastic activation of a sound sources ratio for $n$ iterations of the sound map, and (iv) the calculation of specific sound indicators. The stochastic approach proposed in this study enables the estimation of the temporal sound distribution per sound source. It permits in particular to deduce source-oriented indicators such as the percentage of the time when a given sound source emerges from an urban sound mixture. An example of application of this framework is exposed for a district in the city of Nantes, France. It shows the interest of such approaches, in particular for soundscape and urban sound environment studies.

Keywords: Soundscape; Multisource sound mapping; Stochastic sound modeling
\end{abstract}

\section{Introduction}

The representation of urban sound environments through noise maps became standard since the enactment of the European Noise Directive 2002/49/EC (1). The modeling framework to generate noise maps is now well established: long-term aggregated indicators are calculated based on a collection or estimation of road, air and rail traffic variables, followed by sound emission and propagation calculations (2). This framework however disregards the sound levels variations, and hence prevents the production of statistical or emergence indicators that improve the characterization of urban sound environments (3-5).

In addition, limiting sound maps to traffic sources truncates the reality. A wider range of sound sources, including natural sounds, intervenes when people are asked to describe urban sound environments and evaluate their quality (6-8). Some models link perceptual variables, especially soundscape pleasantness, to the time of presence of typical urban sound sources such as birds or voices and experience shows that natural sounds are often perceived as impacting positively the soundscape pleasantness (9-11). The relative impact of sound sources is however more complex: the positive effect of voices can be for 
31 instance annihilated when voices are too numerous or misfit the context (12). Interactions between sources 32 are also of importance, as shown in (13) between road traffic and industrial noise, or between natural 33 sound sources and road traffic noise (14-17).

34 In consequence, sound mapping recently moved towards multi-sources approaches $(18,19)$. In $(20)$, the 35 presence of sources, categorized into traffic, water, human and bird sounds, is evaluated perceptually at 36 sampled locations and interpolated to create sources-oriented noise maps. A modeling approach is 37 followed in (21): specific noise maps are built for road traffic, fountains, and birds, which are placed by 38 default at trees locations. In recent years, acoustic emission and propagation models have been integrated 39 directly into Geographic Information Systems (GIS) $(22,23)$ and sources-oriented noise maps can benefit 40 from this environment (24). Lavandier et al. related the perceived loudness of the global sound 41 environment and perceived presence time ratio of some sound sources of interest, namely traffic, voices 42 and birds, to geographical indicators (25). If these first researches prove the feasibility and interest of 43 producing source-oriented noise maps, they need further investigations to better consider the sound 44 sources localization and temporal activities, as well as their specific levels and spectral contents. For 45 supporting such researches, it will be helpful that all the source-oriented noise maps are produced using 46 independent emission models for each type of sound source and sharing an identic acoustic propagation 47 model. So that, the new advances would not affect other sound sources emission model and the 48 propagation modeling framework. In addition, the described mapping experiences were based on static 49 approaches that hinder the masking that occurs between sound sources. Indeed, the respective temporal 50 variations of sources are known to strongly impact the fact of hearing or not a sound source within an 51 urban sound mixture, through for instance auditory attention processes (26).

52 We propose a probabilistic modeling framework for producing source-oriented sound maps within an 53 open-source GIS, which shares the same structure, described in section 2, whatever the sound source is. 54 The model is illustrated for the production of traffic, fountains, voices and birds sound maps in section 3. 55 As shown in Section 4, the original probabilistic approach makes it possible to investigate the competition 56 between sound sources, that is to say the probability that a sound source, or a group of sound sources, will 57 be louder than other ones. 


\subsubsection{General presentation}

61 The modeling consists of producing source-oriented sound maps. Our approach is stochastics: a set of $62 n \times k$ sound maps is created, corresponding to $n$ representations of the possible instantaneous sound 63 environment for each of the $k$ considered sound source. Each sound map $i_{k}$ can be seen as the photography 64 at one instant of the possible encountered equivalent 1 -second sound environment for the contribution of a 65 given sound source. Statistics are done on a sufficient representative number of maps to characterize the 66 sound environment where the model input parameters are stable (e.g. constant bird's density during the 67 study period and area). The objective is thus to account for the 1-s time variability of the sound 68 environment to compute original sound environment indicators. The time evolution of sound 69 environments, that is the coherence between two consecutive iterations $i$, is not a target output of the 70 modeling. We follow the same modeling framework in four steps whatever the sound source is.

71 Although the modeling framework contains the same four steps whatever the sound source is, the 72 content of each step differs from one sound source to the other, based on knowledge on its characteristics. 73 In terms of modeling, some sound sources are very well documented in terms of both sound emission and 74 spatial repartition, while other ones require specific modeling. The interest of the approach lies here in the 75 fact that: (i) new sound sources can easily be implemented following the same modeling approach, (ii) 76 each step can be improved through further research without compromising the rest of the modeling chain.

\section{$77 \quad$ 2.1.2. Step 1}

78 The spatial repartition of the potential sound sources (humans, birds, cars, etc.) is defined. To limit the 79 calculation time, the spatial repartition correlates to the density of the sound sources within each zone for 80 a given time period. For instance, in the example illustrated in Figure 1 birds are located within the park 81 where they are more prone to be found. 


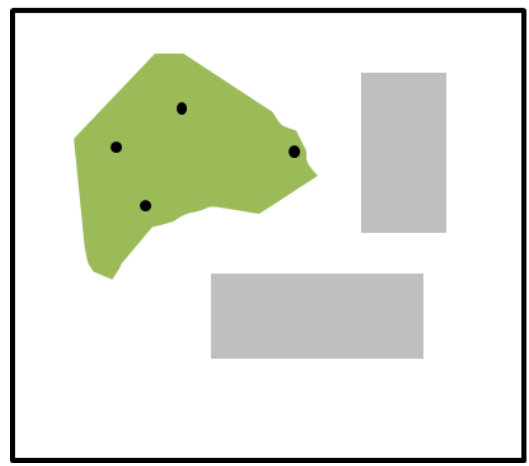

Green space

Building area

- Potential sound source

Figure 1 Graphical resume of Step 1. The potential sound sources,

here birds, are placed in the park.

87 The matrix of attenuation per octave band $(63-8000 \mathrm{~Hz})$, between each couple receivers and potential 88 sound source, is calculated (see Figure 2). We consider that for the stable considered period of time, the acoustic propagation remains unchanged.

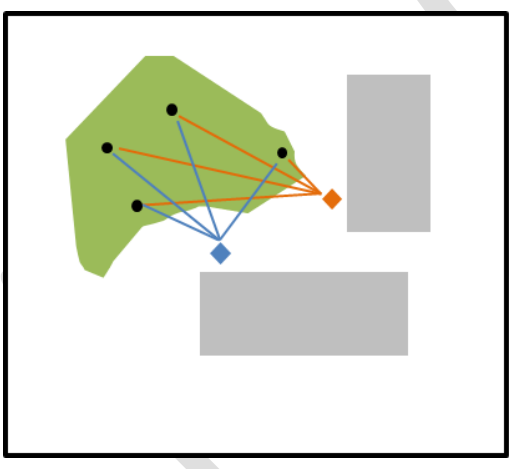

\section{Green space}

Building area

- Potential sound source

- Receivers

— Propagation paths

Figure 2 Graphical resume of Step 2. All the propagation paths are calculated between the couples sound sources / receivers

95 A set of $n$ sound maps is created for each sound source $k$. Each sound map is calculated by activating randomly a proportion of the potential sound sources with respect to knowledge on the activity of the sound source objects. For instance if it is assumed that $30 \%$ of the present humans are speaking during the same second, only $30 \%$ of the located humans randomly selected on the map are activated for a sound map $i$. 
A 1-second equivalent sound power level and spectrum is assigned to each activated sound source, based on knowledge on the sound source: 1-s variability in sound power levels, sound spectrum, prosody for the voices, etc. Each sound map $i$ is calculated by summing the contribution, at each receiver, of each sound source activated at $i$. The individual contribution of each sound source is the sum between the sound power level and the sound propagation attenuation calculated at step 2.

Note again that the activated sound sources vary at each iteration, but that the attenuation matrix is only calculated once, hence strongly limiting the computation time.

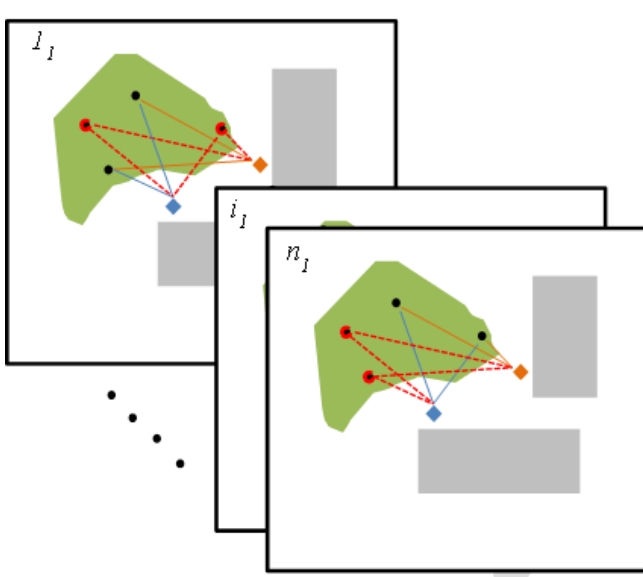

$k=1$,Bird songs

\subsubsection{Step 4} Figure 4.

Figure 3 Graphical resume of Step 3.

A proportion of the birds previously located on the map (step 1) are activated randomly.

The contributions of all the activated sound sources are summed to compute $n$ maps as $n$ possibilities of bird songs sound maps.

Sound level indicators are calculated at each receiver based on the sound maps. The original sound indicators can be statistical levels for each modeled sound sources $\left(L_{10}, L_{50}\right.$ and $L_{90}$, which stand as the sound level exceeded 10, 50 and $90 \%$ of the time, respectively). But also, it can be the proportion of the combinations between the $n x k$ sound maps computed for each sound source where the sound level of a defined sound source is superior to the other ones. For instance, for $\mathrm{x} \%$ of the $n \times k$ computed sound maps the birds sound level is superior to the sound level of the road traffic. A graphical summary is shown in 

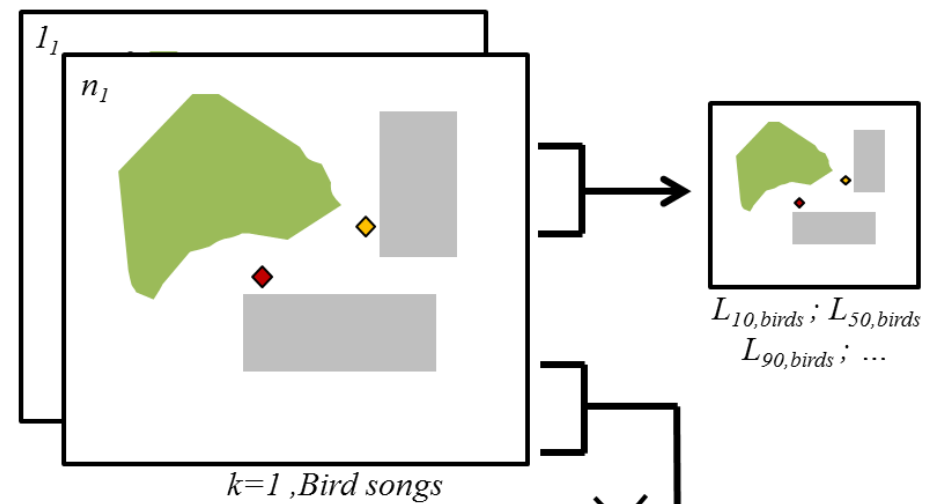

Figure 4 Graphical resume of Step 4.

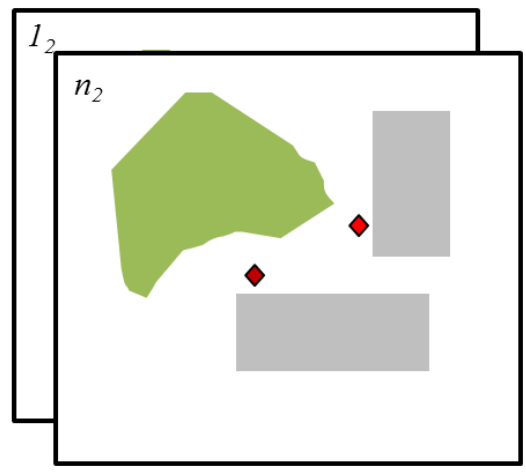

$k=2$, Traffic
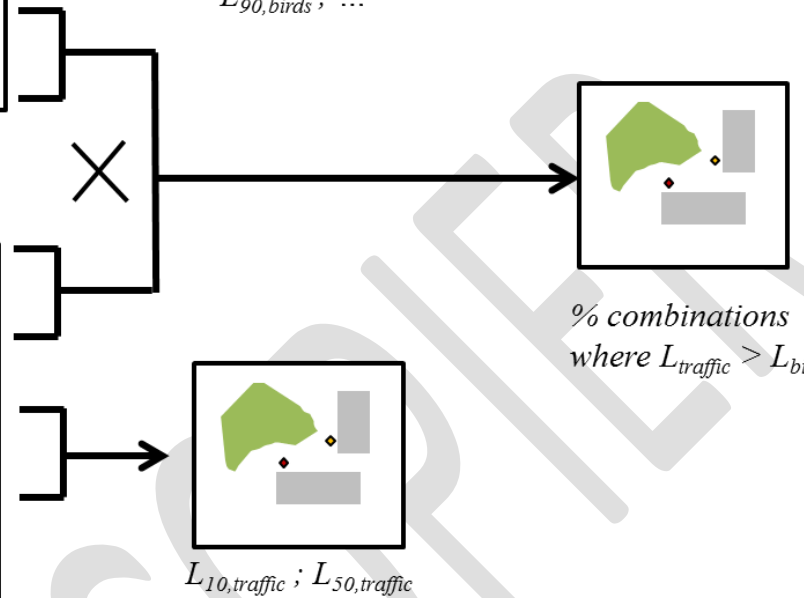

where $L_{\text {traffic }}>L_{\text {birds }}$

$L_{90, \text { traffic }} ; \ldots$

Original sound indicators can be calculated from the sound maps generated

for each sound source but also from the combination between all the generated sound maps.

\subsection{Software environment and sound propagation modeling}

All the modeling steps are implemented within the open-source GIS software OrbisGis ${ }^{1}$. OrbisGIS allows researchers to share their results and build a common platform to analyze sustainable urban development. OrbisGis is compatible with the use of Open Street Map ${ }^{2}$ (OSM) databases (i.e., buildings, roads, etc.) and facilitates the representation of the produced sound maps. In this study, all the geographic information has been imported from the Geofabrik ${ }^{3}$ portal except the traffic data which own to the Nantes 131 city council.

The sound propagation done during the step 2 presented above utilizes the free and open-source 133 Noisemodelling plugin ${ }^{4}$, which has already been developed as an OrbisGis plugin to produce static road traffic noise maps (27). Noisemodelling is designed to produce environmental noise maps on very large

${ }^{1}$ http://orbisgis.org

${ }^{2}$ https://www.openstreetmap.org

${ }^{3}$ http://download.geofabrik.de

${ }^{4}$ http://noise-planet.org/en/noisemodelling.html 
135 urban areas, with few computational resources. The method developed in Noisemodelling is very close to 136 the European CNOSSOS Method for the sound attenuation calculations, see details in (27). A resume of 137 the user-defined parameters that have been used for this study is given in Table 1.

138 Table 1 Values given to user defined parameters used in this study for sound propagation

User defined parameters User configuration for this study

$\begin{array}{lc}\text { Reflection order } & 2 \\ \text { Diffraction Order } & 1 \\ \text { Maximum propagation distance } & 250 \mathrm{~m} \\ \text { Maximum seeking wall } & 50 \mathrm{~m} \\ \text { Buildings height } & 10 \mathrm{~m} \\ \text { Receivers height } & 1.5 \mathrm{~m} \\ \text { Ground absorption } & \mathrm{G}=0 \\ \text { Wall absorption } & \mathrm{G}=0.23\end{array}$

\subsection{Study area and period}

The site is located in Nantes, France. It was chosen because it presents a wide variety of sound environments. It covers an area of about $850 \times 700 \mathrm{~m}$, surrounded on the south by a tramway line and the railway station, on the west by a touristic zone made of a castle and pedestrian streets. The eastern part of the area is a park, "Jardin des Plantes"; a fountain is present on the south of the park. The north boundary of the area is the Place Marechal Joffre. The inner of the area is residential, with 4-floors buildings and low density traffic. A set of 1100 receivers $(20 \times 20 \mathrm{~m})$ is placed following a uniform grid distribution. The grid size has been chosen as a compromise between the computation time and maps sufficiently detailed for these study objectives. The target period studied is a typical weekday in spring around midday.
(1) Park area : « Jardin des
(2) Fountain
(3) Tramway line
(4) Residential block
(5) Railway station
(6) Touristic pedestrian zone
(7) Dense traffic zone

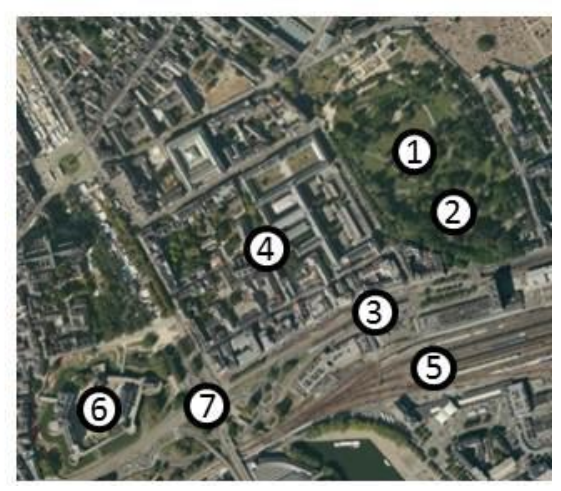

(a)

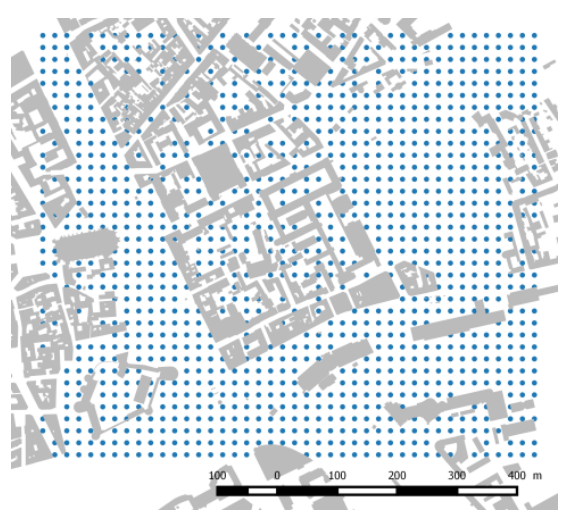

(b) 
The probabilistic modeling framework is illustrated in this paper for road traffic, fountains, voices and bird songs, which are four sound sources that are known to strongly affect the quality of urban sound environments, and that have been the matter of numerous studies. Details of the modeling are presented for each of the four sound sources in this section. For each sound source, we detail the modeling for the steps one and three described previously. The sound propagation (step 2) is not detailed as it does not differ from one sound source to the other. The indicators calculation (step 4) is detailed in Section 4, which presents the final sound maps.

\subsection{Road traffic}

The negative impact of road traffic on urban sound environments is perceptually clearly established $(10,28)$. Note finally that road traffic noise has a secondary negative effect, not clearly quantified yet, which is its masking over the positively perceived sources such as bird songs (29).

\subsubsection{Spatial repartition (Step 1)}

The possible positions for road traffic correspond to the roads documented within Open Street Map in our case. Roads are discretized into point sources as recommended for road traffic noise mapping (2). We choose a $10 \mathrm{~m}$-space resolution, which corresponds to the maximum density encountered on the road network, so that vehicle noise emissions can be individualized. These point sources become potential sound sources for each map iteration, where combined with vehicle densities to activate road traffic sources on the network. The height of the point sources is set to $0.05 \mathrm{~m}$ in accordance with the CNOSSOS standard. Traffic densities are derived from flow rates $\mathrm{Q}$ and speeds $\mathrm{V}$, for different vehicle categories.

171 The key here stands in the access to the traffic data inputs, meaning flow rates, speeds per vehicle 172 category and road segment, which are not necessarily freely available. In this work, data were made 173 available by the city council of Nantes, France, as other cities do.

\subsubsection{Sound emission (Step 3)}

At each computation $i$, the probability to activate a point source is the ratio between the density of the possible sources on the road network (for instance $K_{\max }=0.2 \mathrm{veh} / \mathrm{m}$ if the sources are placed with a space granularity of 5 meters), and the calculated density. For instance with $Q=900 \mathrm{veh} / \mathrm{h}$ and $\mathrm{V}=30 \mathrm{~km} / \mathrm{h}$, the deduced density is $K=0.03 \mathrm{veh} / \mathrm{m}$, and the probability of activation is $15 \%$. Thus, this stochastic approach permits to reproduce the intermittent sound levels encountered within streets where the traffic density is low. 
Once activated, the sound power level and the sound spectrum of a sound source is computed based on the state-of-the-art NMPB noise emission model, in terms of the vehicle category and vehicle speed (30). The implementation results in a map of 1-s emissions, which is extended by means of the attenuation matrix into the noise map $i$ for road traffic.

\subsection{Fountains}

Fountains have a different status from the other elements of street furniture. History has given them strong social, aesthetic and artistic dimensions. Fountains thus constitute key elements of visual amenity and contribute to the identity of gardens and cities. Perceptual studies reveal that fountain sounds are the most favorite ones within urban soundscapes (31). They are also studied as a potential mask for road traffic noise and thus a potential urban facility for improving the sound environments quality by reducing the negative effect of traffic noise (32).

\subsubsection{Spatial repartition (Step 1)}

193 The fountains are represented within Open Street Map and thus easy to position. In the case study only one fountain is present. In this study, the height of the point sources for fountain is set to $0.5 \mathrm{~m}$.

\subsubsection{Sound emission (Step 3)}

The fountain is set to active during all the period of the sound environment we aim to model. The sound spectrum of fountains has been the matter of researches $(33,34)$, which highlighted its high frequency component, between $1 \mathrm{kHz}$ and $4 \mathrm{kHz}$. More in details, the spectrum depends on factors such as the type of fountain, its shape, height of fall, or the material of impact of the water, which often stand as not available information. Under absence of detailed information, we propose by default an average spectrum, inspired from $(33,34)$ and normalized at $90 \mathrm{~dB}$. This corresponds to the spectrum given in Table 2 , which is used by default.

Table 2 Study case sound spectrum for fountains (in dB)

\begin{tabular}{|c|c|c|c|c|c|c|c|c|c|}
\hline & Global & $63 \mathrm{~Hz}$ & $125 \mathrm{~Hz}$ & $250 \mathrm{~Hz}$ & $500 \mathrm{~Hz}$ & $1 \mathrm{kHz}$ & $2 \mathrm{kHz}$ & $4 \mathrm{kHz}$ & $8 \mathrm{kHz}$ \\
\hline $\mathbf{L}_{W}(\mathbf{d B})$ & 90 & 43 & 51 & 62 & 76 & 81 & 85 & 83 & 84 \\
\hline
\end{tabular}
matrix into the sound map $i$ for fountains. In this study case, we consider the fountain as constant, but without any supplementary effort, we could add a variation on the sound level spectra for example, or on the time variation (for instance if during 10 seconds each minute the fountain stops emitting sound). 
210 Sounds derived from human activities are often appreciated components of the urban sound environments, and constitute its identity. Perceptual tests show that amongst human activities, voices are the most quoted of human sounds to describe an ideal soundscape (11). Finally, voices are generally associated to mode lively and animated soundscapes (35).

\subsubsection{Spatial repartition (Step 1)}

215 In an urban environment, most of pedestrians are located on sidewalks and pedestrian zones. Sidewalks are not directly available within Open Street Map database. In our case, they are obtained by subtracting to a large buffer around roads, a narrow buffer around roads and buildings areas. The resulting possible 218 locations for pedestrians are depicted in orange in Figure 6.

The spatial distribution of humans in a city center highly depends on morphologic parameters, such as the functionality of the zone, the shopping areas or the transportation network and soft mode transportation facilities. Space syntax approaches, based on the streets connectivity are found in the literature as good predictors of the traffic volumes within the city $(36,37)$. However, this approach has detractors as it disregards precious metric information and is rather limiting (38); it furthermore does not explicitly account for the functionality of the zones. A microscopic approach based on activity patterns and scheduling and utility maximization is proposed in (39), which however requires specific modeling and higher resources.

As a first approximation, we propose a macroscopic estimation of pedestrian volumes based on available open data furnished by Open street Map. The model parameters are calibrated using open traffic volumes data from the city of Montreal $^{5}$ (more than a hundred counting points). As proposed in (25), the model relies on the density of points of interest (which are shops, railway stations, etc.) within radius of different sizes. Densities are expressed through quadratic kernel functions. For a given item (for instance 232 shops), the density is expressed as in Equation 1.

$$
\sum_{j=1}^{m}\left[\frac{15}{16 * R} *\left(1-\frac{D_{j}^{2}}{R^{2}}\right)\right]
$$

Equation 1

with $D_{j}$ the distance of each item $j$ to the point of interest, $R$ the limit radius (the density being null at 235 $D_{j}=R$ ), and $m$ the number of items within the radius $R$. The model is constructed on the Montreal dataset

\footnotetext{
${ }^{5}$ http://donnees.ville.montreal.qc.ca/
} 
236 (midday data), through multiple linear regressions. Equation 2 shows the constructed model, which 237 expresses the pedestrian flow rate Q (pedestrian per hour), based on the density of shops $K_{s h, 300}$ in a radius 238 of $300 \mathrm{~m}$, the density of public transport stations (metros and tramways) $K_{P T, 400}$ in a radius of $400 \mathrm{~m}$, and 239 the density of restaurants $K_{r t, 400}$ in a radius of $400 \mathrm{~m}$.

$$
Q=5593 K_{s h, 300}+36922 K_{P T, 400}+3042 K_{r t, 400}
$$

241 The model correlates with the pedestrian flowrates from the Montreal dataset $\left(R_{a d j .}^{2}=56 \%, p<.05\right)$, so 242 it will be considered as sufficient for a first approximation of pedestrian flow rates, in the absence of more 243 refined modeling.

244 The pedestrian flow rates determined over the area with Equation 2 are then converted into pedestrian 245 densities. First, the area is partitioned into a grid of $30 \mathrm{~m}$ of side, with a surface $S_{\text {grid }}=900 \mathrm{~m}^{2}$. Then, the 246 number of pedestrians $N_{\text {ped }}$ within each element of the grid is calculated, as

$$
N_{p e d}=\left(Q_{p e d} / V_{p e d}\right) *\left(S_{\text {grid }} / l_{p p}\right)
$$

247 with $Q_{p e d}$ the pedestrian flow rate measured within a band of $l_{p p}$ width set to $20 \mathrm{~m}\left(Q_{p e d}\right.$ will increase as 248 the $l_{p p}$ increases), and the walking speed $V_{p e d}=1.25 \mathrm{~m} \cdot \mathrm{s}^{-1}$. The number of pedestrians placed in the 249 walkable zones is defined based on the ratio within the walkable zones and the grid. These pedestrians are 250 located within the walkable zones of each element of the grid. This ensures that the density increase due to 251 streets tightening is well reproduced. The resulting pedestrian positioning is depicted in Figure 6. The 252 height of the point sources for pedestrian is set to $1.5 \mathrm{~m}$. 


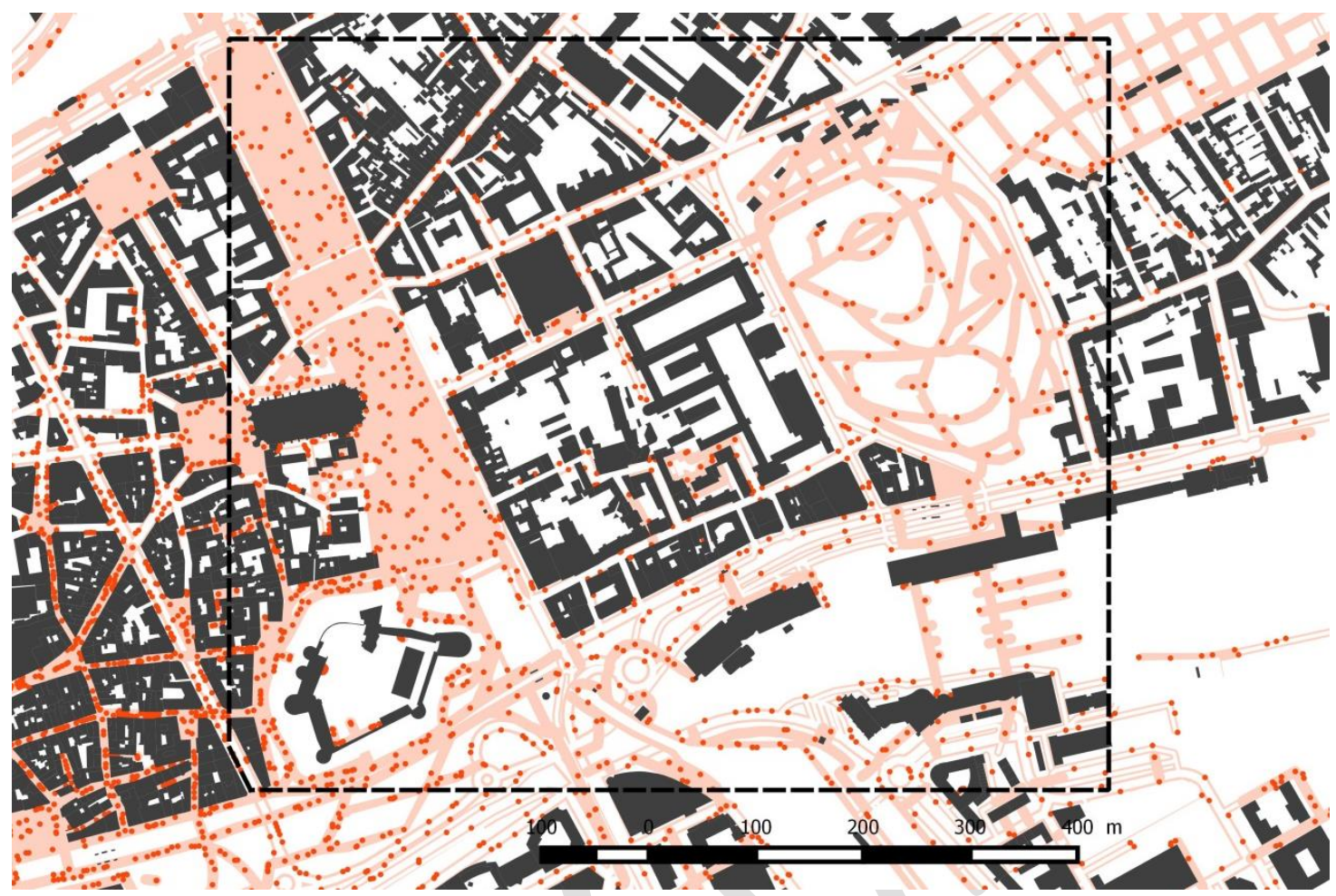

\subsubsection{Sound emission (Step 3)}

within the study area:

zones of walkability (light orange areas), final repartition of pedestrians (orange dots) and receivers area (dotted line).

A relation between the pedestrian density and the number of talking pedestrians has been elaborated by

Qi and Kang (40). It suggests that $30 \%$ of pedestrians talking in a dense crowd is a good approximation.

As a first approximation, this number is retained in the modeling, and for each generated sound map $i$, $30 \%$ of the pedestrian point sources are randomly activated.

The sound spectrum for human voices, categorized into man, woman and child voices, can be found for instance in (41). It shows a maximum of energy within the $250-500 \mathrm{~Hz}$ band frequencies. The sound power level of talking persons varies according to the background sound levels. According to Lazarus (42), raised normal speaking conditions is $60 \mathrm{~dB}$ at 1 meter from the sound source. The Table 3 presents the chosen sound power emissions per octave band associated to voices.

Table 3 Study case sound spectrum for voices (in $\mathrm{dB}$ )

\begin{tabular}{cccccccccc} 
& Global & $\mathbf{6 3 ~ H z}$ & $\mathbf{1 2 5} \mathbf{~ H z}$ & $\mathbf{2 5 0 ~} \mathbf{~ H z}$ & $\mathbf{5 0 0 ~} \mathbf{~ H z}$ & $\mathbf{1 ~} \mathbf{~ H z}$ & $\mathbf{2 ~} \mathbf{~ H z}$ & $\mathbf{4 ~ k H z}$ & $\mathbf{8 ~ k H z}$ \\
\hline $\mathrm{L}_{\mathbf{W}}(\mathbf{d B})$ & $\mathbf{7 1 . 5}$ & 35 & 50 & 53 & 57 & 53 & 50 & 45 & 40
\end{tabular}


The implementation results in a map of 1-s emissions, which is extended by means of the attenuation matrix into the sound map $i$ for pedestrian voices.

\subsection{Bird songs}

273 Bird songs often constitute one of the only contacts with sounds from the bio-phony that urban 274 dwellers experience in their daily life. This explains why bird songs are known to improve the quality of 275 urban sound environments (10), and potentially reduce stress (43).

\section{3.4.1. Spatial repartition (Step 1)}

277 Indicators of urban morphology, especially the building plan area fraction, the green area dispersion 278 index, and the green area perimeters, are found to be correlated to the presence of birds and to the 279 diversity of encountered species $(44,45)$. Thus, without additional knowledge about the bird's spatial 280 repartition, they are placed by default within zones that cover trees located within streets, parks, and the 281 center of urban blocks, which often correspond to private gardens. These zones shown in Figure 7 are 282 found through a combination of Open Street Map layers. Without additional knowledge, one at firsts 283 considers homogeneous spatial distribution of birds as shown in Figure 7. The height of the point sources 284 for birds is set to $4 \mathrm{~m}$.

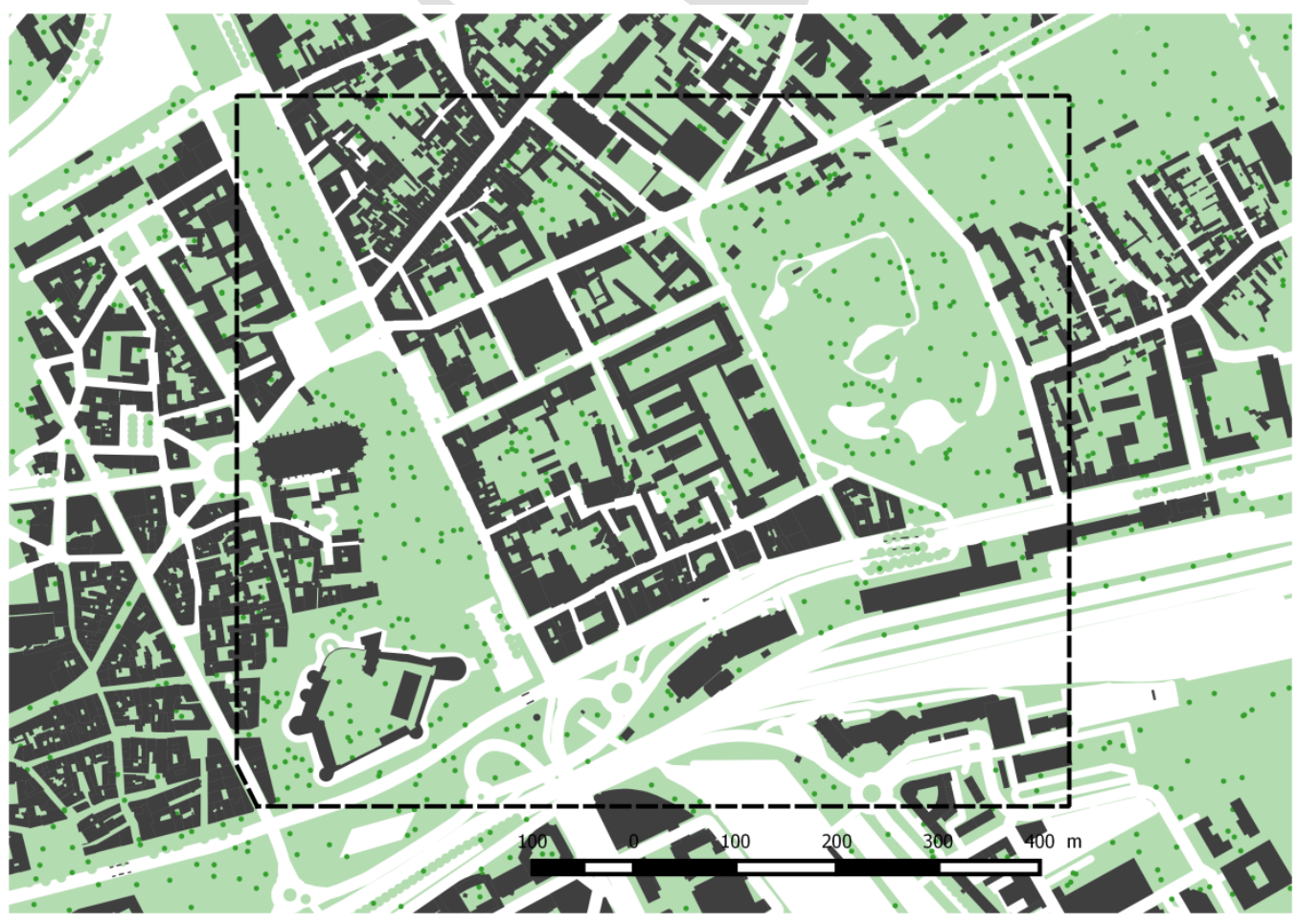


Figure 7 Spatial distribution of bird sound sources within the study area:

The proportion of activated birds corresponds to the number of birds singing at the same time. Without additional knowledge, we consider that $10 \%$ of the potential sound sources are emitting sound.

Calder and Willam linked the acoustic power $\mathrm{P}(\mathrm{mW})$ of singing passerine birds to their weight $m(\mathrm{~g})$, through the formula $P=0.042 . \mathrm{m}^{1.14}(46)$. The singing center frequency $f_{c}(\mathrm{kHz})$ of passerine birds also depends on their weight, through the formula $f_{c}=7.204 . \mathrm{m}^{-0.24}$ (47). For instance, for sparrows whose weight is approximately $35 \mathrm{~g}$, these formula correspond to a sound power level $L_{w}=85.8 \mathrm{~dB}$ and a singing center frequency $f_{c}=3.1 \mathrm{kHz}$. The Table 4 presents the sound power emission level per octave band used in this study to model bird songs.

Table 4 Study case sound spectrum for bird songs (in $\mathrm{dB}$ )

\begin{tabular}{lcccccccccc} 
& Global & $63 \mathrm{~Hz}$ & $125 \mathrm{~Hz}$ & $250 \mathrm{~Hz}$ & $500 \mathrm{~Hz}$ & $1 \mathrm{kHz}$ & $2 \mathrm{kHz}$ & $4 \mathrm{kHz}$ & $8 \mathrm{kHz}$ \\
\hline $\mathrm{L}_{\mathrm{W}}(\mathrm{dB})$ & $\mathbf{8 5 . 5}$ & - & - & - & - & 54 & 80 & 84 & 68
\end{tabular}

The implementation results in a map of 1-s emissions, which is extended by means of the attenuation matrix into the sound map $i$ for birds.

\section{Probabilistic modeling}

\subsection{1-s equivalent sound environment}

The $n$ instantaneous (1-s equivalent) sound maps are generated through the implementation of the presented modeling for fountains, traffic, birds and voices. An example of a predicted instantaneous sound environment is depicted in Figure 8. The stochastic process is visible for instance in Figure 8 (b), in which bird sounds are not homogeneously distributed within the park, because of the randomized activation process. This randomization effect is also visible for road traffic on Figure 8 (d), which shows sound peaks along the main roads, as well as sections with lower sound levels. The effect of the sound attenuation is also visible, for instance sound levels due to road traffic sound sources are very low within the inner courts of buildings. 


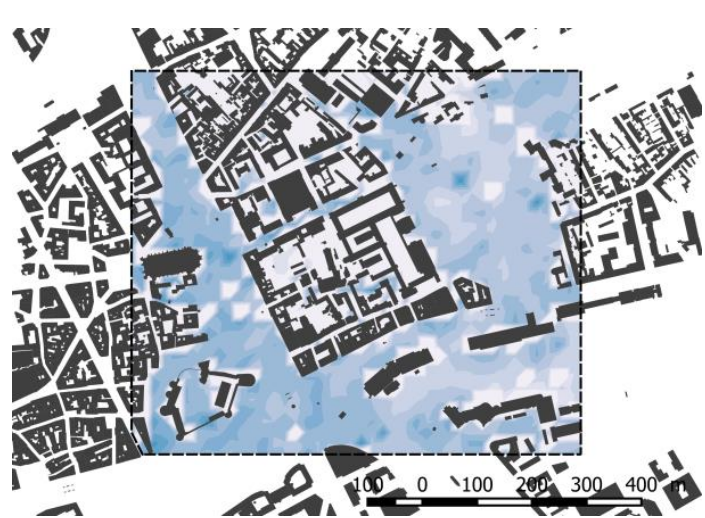

(a)

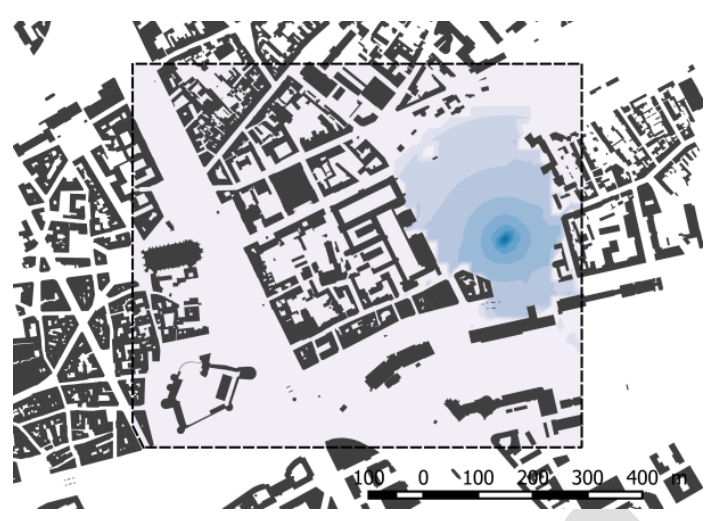

(c)

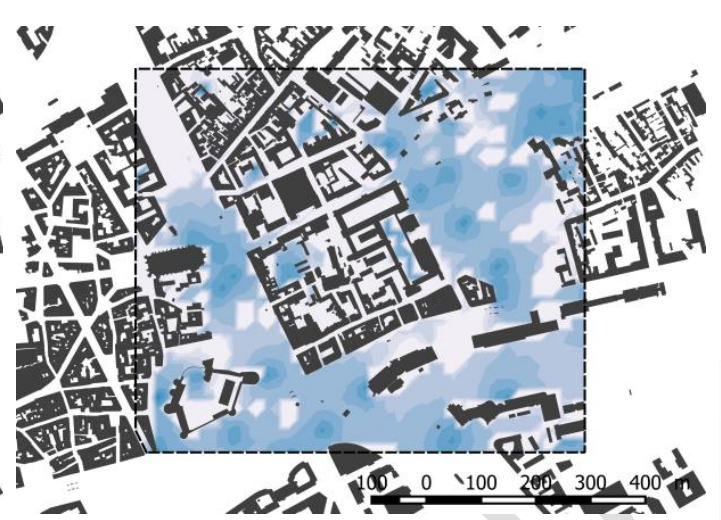

(b)
$\mathrm{dB}$

$<20$ 20-25 25-30 30-35 35-40

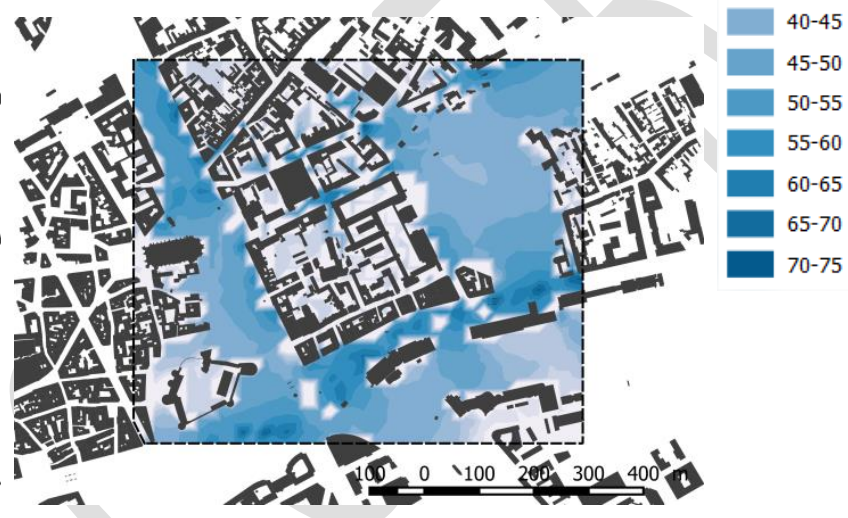

(d)

\subsection{Statistical maps}

The compilation of $n$ iterations ( $n=60$ ) of possible instantaneous sound environments helps calculating statistical sound indicators as described in step 4, which are not accessible through the standard static noise mapping approaches. The number of 60 iterations was chosen because the maps produced were relatively stable after this number of iterations. An example of $L_{50}$ map is provided in Figure 9. Compared with the previous sound maps, and as expected the sound level repartition is much more homogeneous.

These kinds of maps can be useful to evaluate for example the sound levels range of variation in a street for a specific sound source. For instance for road traffic noise, the $L_{10}-L_{90}$ indicator is a meaningful indicator which is usually small for large boulevard, but important in small streets with sporadic car passages. This indicator could also be calculated within the proposed framework. 


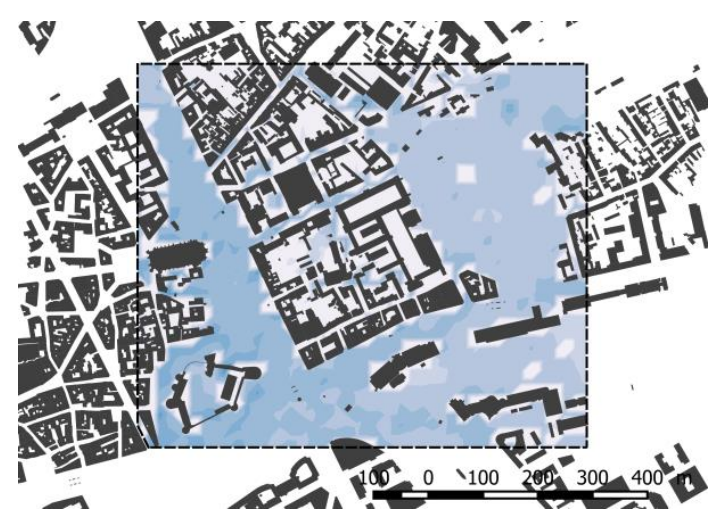

(a)

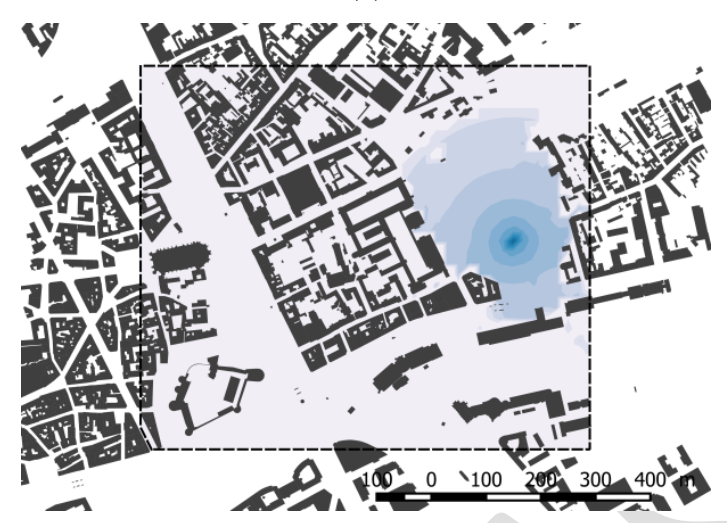

(c)

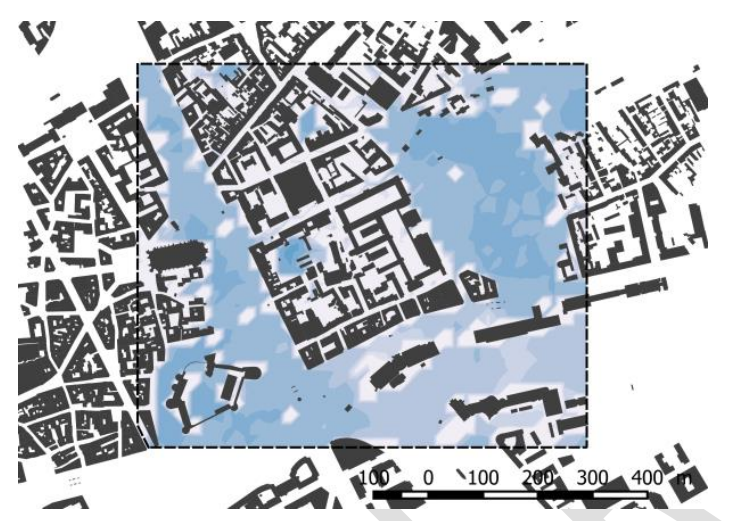

(b)

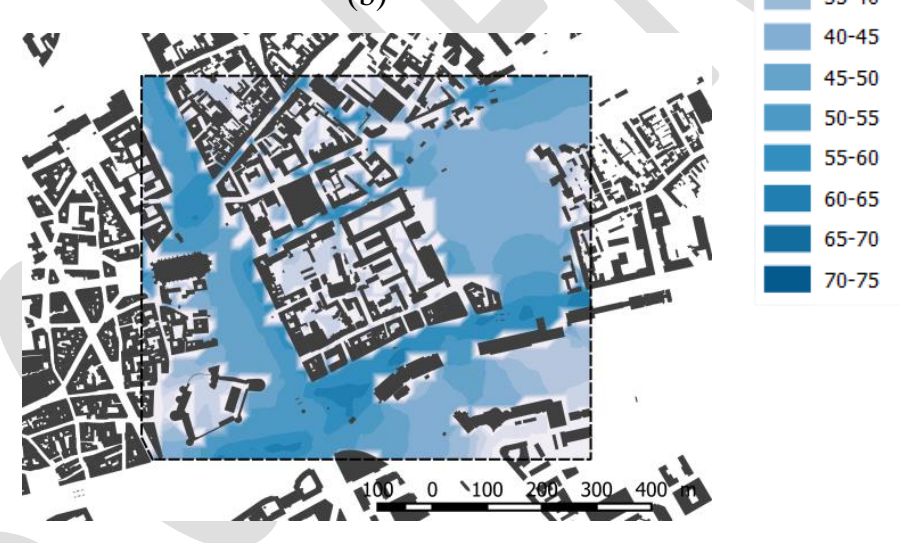

(d)

Figure 9 Four $\mathrm{L}_{50}$ sound maps for (a) pedestrian voices; (b) birds; (c) fountains; (d) traffic

\subsection{Combined sound maps}

In addition, the confrontation of the instantaneous sound maps makes it possible to estimate the probability that a sound source emerges from the global environment sound mixture. For instance, in Figure 8 (b) one can expect that bird sounds, which are not very loud in the south of the park, will be masked by the fountain if we combine these two sound maps.

The criteria to define emergences are as following:

- Bird sounds emerge, for a given instantaneous sound map $i$ and at a given receiver, if the sound pressure level from the birds sound map exceeds the energetic sum of the sound pressure level due to road traffic and fountains at $4 \mathrm{kHz}$ and exceeds $40 \mathrm{~dB}$ (limit set for background urban sound level);

- Voice sounds emerge, for a given instantaneous sound map $i$ and at a given receiver, if the sound pressure level from the voices sound map exceeds the energetic sum of the sound 
pressure level due to road traffic and fountains at 250 or $500 \mathrm{~Hz}$ and exceeds $40 \mathrm{~dB}$ (limit set for background urban sound level);

- Road traffic sounds emerge, for a given instantaneous sound map $i$ and at a given receiver, if at least one octave band of the sound pressure level from the road traffic sound map exceeds the sound pressure level due to fountains and exceeds $40 \mathrm{~dB}$ (limit set for background urban sound level). This third map aims to evaluate road traffic noise masking through fountains.

The computation of 360 combined sound maps gives first approximation of the percentage of the time 349 when a sound source emerges from the global environment sound mixture. Results are depicted in Figure10.

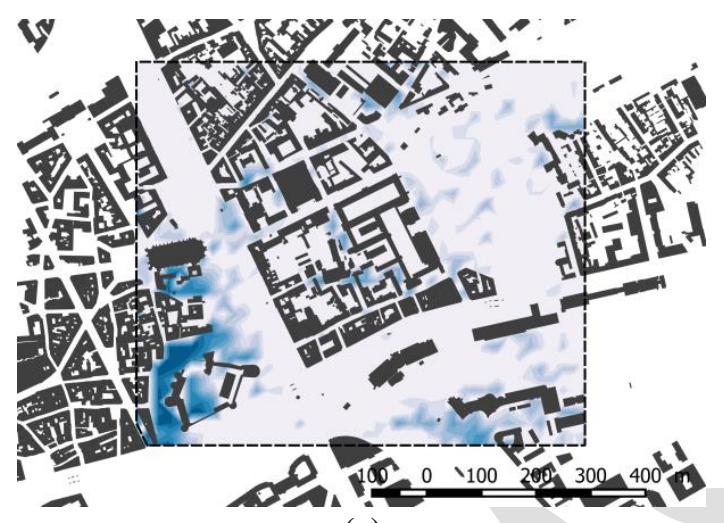

(a)

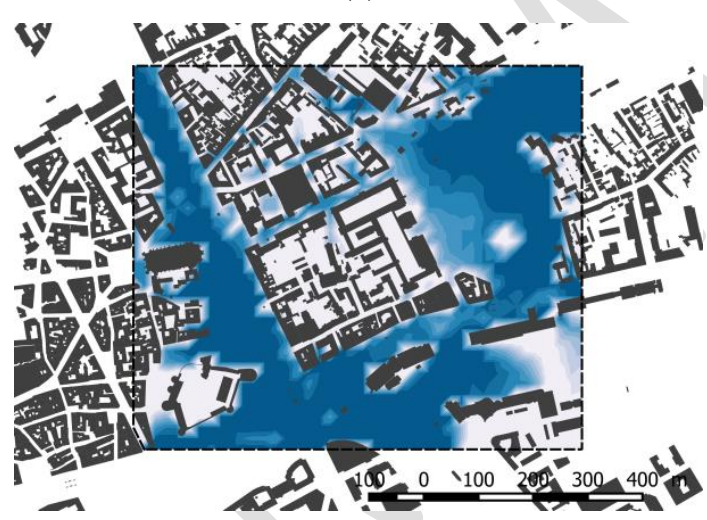

(c)

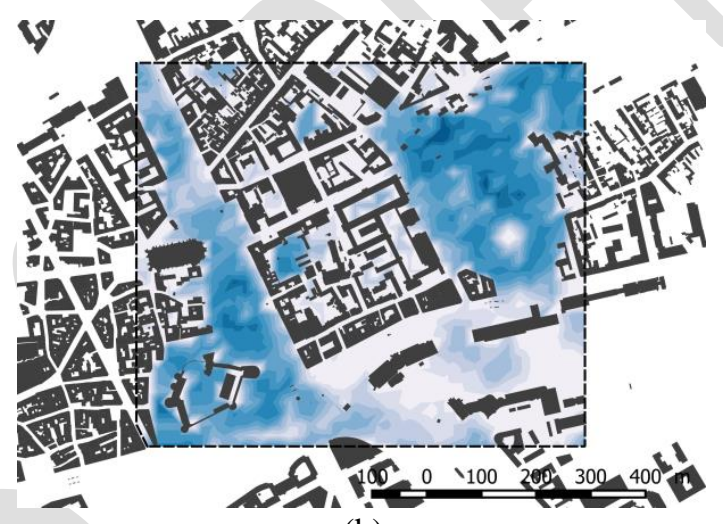

(b)
$<10 \%$ $10 \%-20 \%$ 20\%-30\% $30 \%-40 \%$ $40 \%-50 \%$ $50 \%-60 \%$ $60 \%-70 \%$ $70 \%-80 \%$ $80 \%-90 \%$ $>90 \%$ sound level sound maps. 
In Figure 9 (b), bird sounds are quite homogeneously present over the area (even if louder in parks). In Figure 10 (b), the map proportion where bird sounds emerges is low near the major axis at the south and close to the fountain.

In Figure 10 (a), voices are very present in the south west of the study area which is a pedestrian zone. In the other areas, the competition with the road traffic is very important.

In Figure 10 (c), road traffic noise emerges in nearly all the area. This informs that the road traffic sound levels emerge within the global environment sound mixture. In such situation, the presence of the source is not sufficient to describe the sound environment, but it is very complementary to the sound level indicators produced and illustrated in Figure 9 (d). Interestingly, it can be observed that the propagated sound from the road to the park, at the south-west, is covered by the fountain sound.

\section{Discussion}

Each block of the modeling chain relies inevitably on simplifications. The sound source spatial repartitions and sound power level and spectrum are approximations done to illustrate the framework with realistic values based on the literature and available data. But for other study cases, where results closer to the ground truth are expected, all parameters can be refined using for instance in situ pedestrians, traffic or birds counting, more complex density modeling, but also acoustic measurements of the sound sources of interest. For example, among the outstanding questions we may wonder whether the pedestrian positioning model, derived from the Montreal database, is not too erratic when applied to a European city like Nantes. Also, criteria such as the proportion of birds singing simultaneously (10\%) should be supported by appropriate studies that have not yet been found in the literature.

The modeling blocks are for now completely independent. Thus, interactions between the sound sources are not modeled, except what concerns their masking. However, it is known for instance that the presence of road traffic noise affect for instance birds both in the presence and singing pitches $(46,48)$. This effect can amplify the masking of bird sounds through road traffic noise, what would require modeling some interactions, and thus prioritize the calculation of road traffic noise.

A one-second step was chosen because it is a commonly used value in environmental acoustics and it is thus easier to compare the results obtained with measurement databases. To study masking phenomena, smaller temporal resolution could probably be used, however, the modeling framework proposed in this article will remain valid. 
Other sources can be added, such as wind on the trees or sea sounds, to adapt to the sound environment of any studied urban area. The addition of these two listed sound sources should not be problematic since they are fixed sources, with documented sound spectrums (49,50); but the candidate sources for addition is wide, including bell sounds, rolling suitcases near train stations, etc.

The sound source emergence from a sound mixture is particularly interesting for soundscape studies and it would be of great interest to also include the masking effects into the final step, to present cartography even closer to the perception. Also, linking the produced indicators of emergence to perceived times of presence could be useful as this parameter intervenes for instance within sound pleasantness models (10).

The stochastic approach permits to add variability on input parameter. This can be used to add associated uncertainty as proposed in (51). For instance, variability on voices sound source parameters could be included using $50 \%$ of men and $50 \%$ of women voice spectrums.

Finally, in order to promote reproducible research and the reuse of the framework, all data and code are available on Github ${ }^{6}$.

\section{Conclusion}

A modeling framework adaptable to any of the sound sources encountered in urban areas has been proposed and applied on a city district of Nantes, France. It consists of four steps: (Step 1) a spatial distribution of the potential sound source of interest; (Step 2) the calculation of a sound propagation matrix; (Step 3) the stochastic activation of the sound sources for $n$ iterations of the sound map; (Step 4) the calculation of original sound indicators, some of which coming from the combination of computed sound maps.

The proposed framework integrates independent modeling blocks that leave open the improvements at each step of the modeling, or the choice between different models based on the available input data. The stochastic approach also enables the estimation of sound levels variability. The final original proposed sound maps permit to the reader to observe if a specific sound source is emerging from the global sound mixture, and so give very complementary information to the well-known sound level maps.

\footnotetext{
${ }^{6}$ https://github.com/pierromond/NoiseModelling/wiki/12---Stochastic-Multi-Source-Sound-Mapping
} 
The authors also would like to thank Solène Croci, and Jean-Michel Auberlet for fruitful discussion on birds and pedestrian spatial repartition in urban environment.

\section{References}

413
1. EC. Directive 2002/49/EC of the European parliament and the Council of 25 June 2002 relating to the assessment and management of environmental noise. Off J Eur Communities. 2002;189(12):1225.

2. Kephalopoulos S, Paviotti M, Anfosso-Lédée F, Van Maercke D, Shilton S, Jones N. Advances in the development of common noise assessment methods in Europe: The CNOSSOS-EU framework for strategic environmental noise mapping. Sci Total Environ. 2014 Jun;482-483:400-10.

3. Liu J, Kang J, Luo T, Behm H, Coppack T. Spatiotemporal variability of soundscapes in a multiple functional urban area. Landsc Urban Plan. 2013;115:1-9.

4. Can A, Leclercq L, Lelong J, Defrance J. Accounting for traffic dynamics improves noise assessment: Experimental evidence. Appl Acoust. 2009;70:821-9.

5. Brocolini L, Lavandier C, Quoy M, Ribeiro C. Measurements of acoustic environments for urban soundscapes: choice of homogeneous periods, optimization of durations, and selection of indicators. J Acoust Soc Am. 2013;134(1):813-21.

6. Nilsson ME, Botteldooren D, De Coensel B. Acoustic Indicators of Soundscape Quality and Noise Annoyance in Outdoor Urban Areas. In: 19th International Congress on Acoustics. 2007.

7. Ricciardi P, Delaitre P, Lavandier C, Torchia F, Aumond P. Sound quality indicators for urban places in Paris cross-validated by Milan data. J Acoust Soc Am. 2015 Oct;138(4):2337-48.

8. Brown AL, Kang J, Gjestland T. Towards standardization in soundscape preference assessment. Appl Acoust. 2011 May 1;72(6):387-92.

9. Lavandier C, Defreville B, Defréville B. The contribution of sound source characteristics in the assessment of urban soundscapes. Acta Acust United Acust. 2006 Nov;92(6):912-21.

10. Aumond P, Can A, De Coensel B, Botteldooren D, Ribeiro C, Lavandier C. Modeling Soundscape Pleasantness Using perceptual Assessments and Acoustic Measurements Along Paths in Urban Context. Acta Acust United Acust. 2017 May 1;103(3):430-43.

11. Guastavino C. The Ideal Urban Soundscape: Investigating the Sound Quality of French Cities. Acta Acust United Acust. 2006;92:945-51.

12. Pérez-Martínez G, Torija AJ, Ruiz DP. Soundscape assessment of a monumental place: A methodology based on the perception of dominant sounds. Landsc Urban Plan. 2018 Jan 1;169(Supplement C):12-21. 
13. Morel J, Marquis-Favre C, Gille L-A. Noise annoyance assessment of various urban road vehicle pass-by noises in isolation and combined with industrial noise: A laboratory study. Appl Acoust. 2016 Jan 1;101(Supplement C):47-57.

14. Coensel BD, Vanwetswinkel S, Botteldooren D. Effects of natural sounds on the perception of road traffic noise. J Acoust Soc Am. 2011;129(4):EL148-EL148.

15. Hao Y, Kang J, Wörtche H. Assessment of the masking effects of birdsong on the road traffic noise environment. J Acoust Soc Am. 2016 Aug 1;140(2):978-87.

16. You J, Lee PJ, Jeon JY. Evaluating water sounds to improve the soundscape of urban areas affected by traffic noise. Noise Control Eng J. 2010;58(5):477-477.

17. Jeon JY, Lee PJ, You J, Kang J. Perceptual assessment of quality of urban soundscapes with combined noise sources and water sounds. J Acoust Soc Am. 2010;127(3):1357-66.

18. Licitra G. Noise mapping in the EU: models and procedures. CRC Press; 2012.

19. Kang J, Aletta F, Gjestland TT, Brown LA, Botteldooren D, Schulte-Fortkamp B, et al. Ten questions on the soundscapes of the built environment. Build Environ. 2016 Nov 1;108(Supplement C):284-94.

20. Hong JY, Jeon JY. Exploring spatial relationships among soundscape variables in urban areas: A spatial statistical modelling approach. Landsc Urban Plan. 2017 Jan;157:352-64.

21. Aletta F, Kang J. Soundscape approach integrating noise mapping techniques: a case study in Brighton, UK. Noise Mapp. 2015 Jan;2(1):1-12.

22. Fortin N, Bocher E, Picaut J, Petit G, Dutilleux G. An opensource tool to build urban noise maps in a GIS. Open Source Geospatial Res Educ Symp OGRS. 2012 Oct;9p, cartes-9p, cartes.

23. de Kluijver H, Stoter J. Noise mapping and GIS: optimising quality and efficiency of noise effect studies. Comput Environ Urban Syst. 2003 Jan;27(1):85-102.

24. Hong JY, Jeon JY. Soundscape mapping in urban contexts using GIS techniques. Inter-Noise 2014. 2014;5-5.

25. Lavandier C, Aumond $\mathrm{P}$, Gomez $\mathrm{S}$, Dominguès $\mathrm{C}$. Urban soundscape maps modelled with georeferenced data. Noise Mapp [Internet]. 2016 [cited 2017 Mar 16];3(1). Available from: https://www.degruyter.com/view/j/noise.2016.3.issue-1/noise-2016-0020/noise-2016-0020.xml

26. Oldoni D, De Coensel B, Boes M, Rademaker M, De Baets B, Van Renterghem T, et al. A computational model of auditory attention for use in soundscape research. J Acoust Soc Am. 2013 Jul 1;134(1):852-61.

27. Fortin N, Bocher E, Petit G, Gouge A, Picaut J, Dutilleux G. Urban noise maps in a GIS. In: Open Source Geospatial Research and Education Symposium [Internet]. 2012. p. 227-35. Available from: https://www.researchgate.net/publication/278381211_Urban_noise_maps_in_a_GIS

28. Nilsson ME, Berglund B. Soundscape quality in suburban green areas and city parks. Acta Acust United Acust. 2006;92(6):903-11. 
29. Assessment of the masking effects of birdsong on the road traffic noise environment. J Acoust Soc Am. 2016 Aug 1;140(2):978-87.

30. Dutilleux G, Defrance J, Ecotière D, Gauvreau B, Bérengier M, Besnard F, et al. NMPB-Routes2008: The Revision of the French Method for Road Traffic Noise Prediction. Acta Acust United Acust. 2010 May;96(3):452-62.

31. KANG J. On the diversity of urban waterscape. In: d'Acoustique SF, editor. Acoustics 2012 [Internet]. Nantes, France; 2012 [cited 2017 Mar 14]. Available from: https://hal.archivesouvertes.fr/hal-00811058

32. Galbrun L, Ali TT. Acoustical and perceptual assessment of water sounds and their use over road traffic noise. J Acoust Soc Am. 2013 Jan;133(1):227-37.

33. Galbrun L, Ali TT. Acoustical and perceptual assessment of water sounds and their use over road traffic noise. J Acoust Soc Am. 2013 Jan;133(1):227-37.

34. Watts GR, Pheasant RJ, Horoshenkov KV, Ragonesi L. Measurement and Subjective Assessment of Water Generated Sounds. Acta Acust United Acust. 2009 Nov 1;95(6):1032-9.

35. Axelsson Ö, Nilsson ME, Berglund B. A principal components model of soundscape perception. $\mathbf{J}$ Acoust Soc Am. 2010 Nov;128(5):2836-2836.

36. Jiang B. Ranking spaces for predicting human movement in an urban environment. Int J Geogr Inf Sci. 2009 Jul 1;23(7):823-37.

37. Raford N, Ragland D. Space Syntax: Innovative Pedestrian Volume Modeling Tool for Pedestrian Safety. Transp Res Rec J Transp Res Board. 2004 Jan 1;1878:66-74.

38. Ratti C. Space Syntax: Some Inconsistencies. Environ Plan B Plan Des. 2004 Aug 1;31(4):487-99.

39. Hoogendoorn SP, Bovy PHL. Pedestrian route-choice and activity scheduling theory and models. Transp Res Part B Methodol. 2004 Feb;38(2):169-90.

40. Meng Q, Kang J. The influence of crowd density on the sound environment of commercial pedestrian streets. Sci Total Environ. 2015 Apr 1;511:249-58.

41. Speech Levels in Various Noise Environments [Internet]. [cited 2017 Aug 8]. Available from: http://www.auditory.org/mhonarc/2008/msg00529.html

42. Lazarus H. Prediction of Verbal Communication is Noise-A review: Part 1. Appl Acoust. 1986 Jan 1;19(6):439-64.

43. Alvarsson JJ, Wiens S, Nilsson ME. Stress Recovery during Exposure to Nature Sound and Environmental Noise. Int J Environ Res Public Health. 2010 Mar;7(3):1036-46.

44. Hao Y, Kang J, Krijnders JD. Integrated effects of urban morphology on birdsong loudness and visibility of green areas. Landsc Urban Plan. 2015 May;137:149-62.

45. Pellissier V, Cohen M, Boulay A, Clergeau P. Birds are also sensitive to landscape composition and configuration within the city centre. Landsc Urban Plan. 2012 Feb;104(2):181-8. 
513 46. Calder WA. The Scaling of Sound Output and Territory Size: Are They Matched? Ecology.

$514 \quad 1990 ; 71(5): 1810-6$.

515 47. Wallschläger D. Correlation of song frequency and body weight in passerine birds. Experientia.

$516 \quad 1980$ Apr 1;36(4):412-412.

517 48. Gentry KE, McKenna MF, Luther DA. Evidence of suboscine song plasticity in response to traffic

518 noise fluctuations and temporary road closures. Bioacoustics. 2017 Apr 17;0(0):1-17.

519 49. Bolin K. Prediction Method for Wind-Induced Vegetation Noise. Acta Acust United Acust. 2009 Jul

$520 \quad 1 ; 95(4): 607-19$.

521 50. Bolin K, Åbom M. Air-borne sound generated by sea waves. J Acoust Soc Am. 2010

522 May;127(5):2771-9.

523 51. Le Courtois F, Kinda G, Stephan Y. Statistical ambient noise maps from traffic at world and basin scales. In Cambridge, UK: Institute Of Acoustics; 2016. 